\title{
Novel aspects of age-protection by spermidine supplementation are associated with preserved telomere length
}

\author{
Alexander Wirth (D) B Bettina Wolf • Cheng-Kai Huang • Silke Glage • Sebastian J. \\ Hofer • Marion Bankstahl • Christian Bär • Thomas Thum • Kai G. Kahl • Stephan J. \\ Sigrist • Frank Madeo • Jens P. Bankstahl • Evgeni Ponimaskin $(\mathbb{D}$
}

Received: 14 May 2020 / Accepted: 2 December 2020 / Published online: 31 January 2021

(C) The Author(s) 2021

\begin{abstract}
Ageing provokes a plethora of molecular, cellular and physiological deteriorations, including heart failure, neurodegeneration, metabolic maladaptation, telomere attrition and hair loss. Interestingly, on the molecular level, the capacity to induce autophagy, a cellular recycling and cleaning process, declines with age across a large spectrum of model organisms and is
\end{abstract}

Alexander Wirth and Bettina Wolf shared first authorship

Jens P. Bankstahl and Evgeni Ponimaskin shared corresponding authorship

A. Wirth · E. Ponimaskin

Cellular Neurophysiology, Hanover Medical School,

Carl-Neuberg-Straße 1, 30625 Hannover, Germany

B. Wolf · J. P. Bankstahl $(\bowtie)$

Preclinical Molecular Imaging, Department of Nuclear Medicine, Hanover Medical School, Carl-Neuberg-Straße 1, 30625 Hannover, Germany

e-mail: Bankstahl.Jens@mh-hannover.de

C.-K. Huang $\cdot$ C. Bär $\cdot$ T. Thum

Institute of Molecular and Translational Therapeutic Strategies,

Hanover Medical School, Carl-Neuberg-Straße 1,

30625 Hannover, Germany

S. Glage $\cdot$ M. Bankstahl

Institute for Laboratory Animal Science, Hanover Medical School, Carl-Neuberg-Straße 1, 30625 Hannover, Germany

\section{S. J. Hofer $\cdot$ F. Madeo}

Institute of Molecular Biosciences, Karl-Franzens-Universität

Graz, Humboldtstraße 50/EG, 8010 Graz, Austria thought to be responsible for a subset of age-induced changes. Here, we show that a 6-month administration of the natural autophagy inducer spermidine in the drinking water to aged mice is sufficient to significantly attenuate distinct age-associated phenotypes. These include modulation of brain glucose metabolism, suppression of distinct cardiac inflammation parameters,

C. Bär · T. Thum

REBIRTH Center for Translational Regenerative Medicine, Hanover Medical School, Carl-Neuberg-Straße 1, 30625 Hannover, Germany

T. Thum

Fraunhofer Institute for Toxicology and Experimental Medicine (ITEM), Nikolai-Fuchs-Straße 1, 30625 Hannover, Germany

K. G. Kahl

Dept. of Psychiatry; Social Psychiatry and Psychotherapy, Hanover Medical School, Carl-Neuberg-Straße 1,

30625 Hannover, Germany

\section{S. J. Sigrist}

Freie University Berlin, Institute of Biology, Takusstraße 6, 14195 Berlin, Germany

E. Ponimaskin $(\bowtie)$

Institute of Neuroscience, Lobachevsky State University of Nizhny Novgorod, Gagarin ave. 23, Nizhny Novgorod, Russian Federation 603950

e-mail: Ponimaskin.Evgeni@mh-hannover.de 
decreased number of pathological sights in kidney and liver and decrease of age-induced hair loss. Interestingly, spermidine-mediated age protection was associated with decreased telomere attrition, arguing in favour of a novel cellular mechanism behind the anti-ageing effects of spermidine administration.

Keywords Spermidine $\cdot$ Ageing $\cdot$ Hair growth $\cdot$ Glucose metabolism $\cdot$ PET $\cdot$ Cardiac telomeres

\section{Introduction}

As average human life expectancy increases constantly, understanding the mechanisms underlying physiological ageing has gained a lot of scientific interest [20]. Ageing is a natural process characterised by a progressive impairment of cellular functions leading to a timedependent functional decline in tissue and organ homeostasis. Pathological changes in numerous cellular processes, including mitochondrial dysfunction, telomere shortening, dysregulation of nutrient-sensing and affected intracellular signalling pathways, are characteristic features of ageing in most organisms [31]. Among the many deteriorating cellular processes in ageing, autophagy plays a major role, as its restoration has been shown to counteract manifold ageing phenotypes and is capable of prolonging health and lifespan in various model organisms. Thus, autophagy-inducing interventions have become a major field of gerontology research. Overall, ageing-related deteriorations at the cellular level arguably represent the major risk factor for most noncommunicable diseases [23].

Ageing however is a multifaceted process, taking place at multiple molecular, cellular and organismal levels, with organs and specific tissues being affected to a different degree. In this regard, it is becoming increasingly apparent that the brain is particularly vulnerable and highly susceptible to pathological agerelated changes, making advanced age the major risk factor for developing neurodegenerative diseases. Accordingly, the number of the individuals affected by ageing-associated neurodegenerative brain disorders, importantly Alzheimer's disease, is constantly increasing during the last decades [2], with dementia-like diseases meanwhile ranking among the top five causes of death [66].

In addition to neurodegenerative disorders, ageing represents the dominant risk factor for the development of cardiovascular diseases as well. Ageing produces numerous changes in the human heart at the molecular, structural and functional level [12]. The most common age-related alterations in the heart are cardiac hypertrophy (in particular affecting left ventricle), fibrosis and maladaptive remodelling leading to diastolic dysfunction and heart failure [54].

To date, the most robust intervention towards an increase in the healthy lifespan is caloric restriction without malnutrition [27]. However, the compliance of caloric restriction in human is low as it is rarely compatible with most people's daily life. Thus, food supplements acting as caloric restriction mimetics (CRM) might provide attractive alternatives [32, 35, 40]. Particularly, the naturally occurring polyamine spermidine has been shown to extend life- and health span in worms, flies and mice [30, 56]. Levels of endogenous spermidine decline with age in model organisms and in humans (for review, see Madeo et al. [34]). Spermidine action has been linked to the modulation of reactive oxygen species, DNA replication, transcription and translation, anti-inflammatory properties, altered mitochondrial function, improved proteostasis, increased hypusination and the induction of autophagy [13, 37, $46,69]$. Furthermore, analysis in ageing mice has shown that spermidine feeding not only prolongs the lifespan but also exerts cardio-protective effects as well as protective measures on the synaptic and mitochondrial status of ageing mice $[12,34,36]$.

In this study, we aimed to analyse potentially beneficial impact of prolonged spermidine administration on commonly age-affected organ systems, including the heart, the liver, the kidney and the brain. Therefore, we analysed the putative effects of spermidine supplementation in two cohorts of aged mice comparing animals after 6 months of supplementation, starting at an advanced age of 17/18 months, with age-matched nontreated mice. We also analysed an additional cohort of 6-month-old non-treated mice as 'young controls'. Our results demonstrate a protective role of spermidine consumption against age-related hair loss. In addition, analysis of the metabolic changes in the brain using $\left[{ }^{18} \mathrm{~F}\right]$ fluoro-2-deoxy-D-glucose positron emission tomography ( $\left.\left[{ }^{18} \mathrm{~F}\right] \mathrm{FDG}-\mathrm{PET}\right)$ revealed that spermidinetreatment affected glucose uptake in the brain of aged mice towards the level observed in young animals. Furthermore, we observed cardio-protective effects of spermidine-treatment at histological levels, which were accompanied by a decrease in telomere attritionin in 
comparison to untreated aged animals. These results further underline the potential of spermidine supplementation to impact age-induced deteriorations of the brain, the liver, the kidney and the heart.

\section{Material and methods}

Animals

Male C57Bl/6JRj mice were purchased from Janvier labs at an age of either 6 months or 17 months. The 6month-old group served as young control cohort and received no spermidine supplementation. The 17month-old mice were randomised into two groups: one group was given drinking water supplemented with $3 \mathrm{mM}$ spermidine $\left(\mathrm{spd}^{+}\right)$(Sigma-Aldrich, aqueous stock solution, $\mathrm{pH}$ 7.2) ad libitum over the whole test period. The other group received normal tap water. The initial number of animals each group was 11 according to power analyses [15] $\left(\mathrm{G}^{*}\right.$ power; $n=11$, effect size $=$ $1.5, \alpha=0.05,1-\beta=0.95)$. All groups were kept at a $14 / 10$ light-dark-cycle and standard chow containing $22.5 \%$ protein, $5.1 \%$ fat, $4.5 \%$ fibre and $6.1 \%$ ash (Altromin \#1314). In general, four mice were housed per cage. Of note, mice were separated into single cages at least 3 weeks prior to the final experiments to avoid barbering. PET experiments were conducted at an age of 6 or 23 months, whereas the histology sampling took place at an age of 24/25 months. Husbandry and procedures involving animals were carried out according to the German Animal Welfare Legislation as set forth by the European Convention for the Protection of Vertebrate Animals used for Experimental and Other Scientific Purposes, Council of Europe, ETS no.123, appendix VIII and according to national regulations and standards. All experiments were approved by the local Institutional Animal Care and Research Advisory Committee and by the local government, namely the Lower Saxony State Ministry of Food, Agriculture and Consumer Protection in consultation with the Animal Protection Committee with the approval ID: 33.12-42502-04-16/2206.

\section{Cohort parameters}

Each mouse was weighed once at the age of 17 month and at the age of 23 month using a table balance (CM 320-1N, Kern). The amount of consumed water was measured within a 2-week long-lasting time period at the end of the experimental phase. The amount of water was measured twice a week for each mouse. To quantify the fur coverage, images of the mice (top view) were taken during the final experiment. Those images were converted into 8-bit files and analysed using FIJI. First, the area of the visible body (top view; excluding ears, claws, tail) was quantified. Second, the fur-uncovered area was quantified by drawing a ROI manually around the less hairy part of the body. Total area was set to $100 \%$ and fur-uncovered area was quantified in relation to the whole body.

\section{PET imaging}

PET images were acquired using a small animal PET/ computer tomography (CT) camera (Inveon, Siemens). Mice were anesthetised with $1.5-2.5 \%$ isoflurane in humidified oxygen. Monitoring of respiration (BioVet, $\mathrm{m} 2 \mathrm{~m}$ imaging) was used to adjust anaesthesia levels to maintain a stable respiration rate. Mice were positioned prone in a continuously warmed double mouse chamber (Minerve) with the brain in the centre field of view. $\left[{ }^{18} \mathrm{~F}\right]$ FDG was injected via a custom-made catheter inserted into a lateral tail vein $(12.82 \pm 0.71 \mathrm{MBq})$. The scan was started with the beginning of the radiotracer injection and dynamic data were acquired for $60 \mathrm{~min}$ in 32 frames $(5 \times 2 \mathrm{~s}, 4 \times 5 \mathrm{~s}, 3 \times 10 \mathrm{~s}, 8 \times 30 \mathrm{~s}$, $5 \times 60 \mathrm{~s}, 4 \times 300 \mathrm{~s}$ and $3 \times 600 \mathrm{~s}$ ). For image reconstruction, iterative ordered subset expectation maximization algorithm followed by 18 iterations of maximum a posteriori (OSEM3D/fastMAP) applying standard corrections for decay, random and scatter was used. For attenuation correction we referred to a $20 \mathrm{~min}{ }^{57} \mathrm{Co}$ transmission scan. After PET, a low-dose CT scan was performed to provide anatomical information for image analysis. Directly after induction of anaesthesia and at the end of the imaging session, blood glucose levels were measured by a micro puncture of the saphenous vein (Conrour XT®, Bayer Consumer Care) and averaged for image analysis. In total, 22 mice were subjected to $\left[{ }^{18}\right.$ F]FDG PET (young: $n=9$; aged: $n=6$; aged + $\left.\operatorname{spd}^{+}: n=6\right)$. One mouse of the aged group died during the scan, and due to movement artefacts at the beginning of the scan in one mouse of the aged $+\mathrm{spd}^{+}$group, only uptake analysis was possible. The whole experiment including analyses was performed in a blinded fashion. 
PET image analysis

Imaging data were analysed using PMOD software (PMOD 3.703). A region of interest was defined for the left ventricular myocardium, and for brain analysis, images were co-registered to an MRI-based volumes of interest (VOI) -atlas [38]. Uptake was analysed in minutes 50-60 after tracer injection as percent injected dose per cubic centimetre of tissue [\% $\% \mathrm{ID} / \mathrm{cc}]$. In addition, kinetic modelling was performed. Image input function of the blood was derived from a $18 \mathrm{~mm}^{3}$ cylindrical VOI placed on the inferior vena cava superior to the renal branches, excluding the last three time frames. For regional brain analysis, blood time activity curves (TAC) were fitted to a two-tissue compartment model setting t 4 to 0 . Additionally, curves were fitted to the Patlak kinetic model. Brain influx rate constant $K_{\mathrm{i}}$ $[\mathrm{ml} / \mathrm{g} / \mathrm{min}]$ was the graphically defined Patlak slope, and the metabolic rate of glucose uptake $\mathrm{MR}_{\mathrm{Glu}}[\mu \mathrm{mol} / \mathrm{min} /$ $100 \mathrm{~g}]$ was calculated as $K_{\mathrm{i}} \times$ blood glucose / LC, whereas LC is the lumped constant equally 0.67 as estimated for rodents [59]. Both models revealed highly similar results (data not shown). Additional parametric maps using Patlak graphical analysis on a voxel level were calculated with PMOD.

Average images and statistical parametric mapping (SPM) were calculated using the MATLAB software (The MathWorks) and SPM12 (University College London). For SPM, differences between groups were calculated by unpaired 2 -sample $t$ tests with a significance level threshold of 0.05 (uncorrected for multiple comparisons). Minimum voxel cluster size was set to 50 and threshold of $t$ maps was set according to the degrees of freedom of the comparison.

Preparations of tissue paraffin sections

At the dedicated time points, the animals were sacrificed. Tissues were fixed in neutral buffered $4 \%$ paraformaldehyde for at least $24 \mathrm{~h}$. After trimming according to the Registry of Industrial Toxicology Animal-Data recommendation and dehydration (Shandon Hypercenter, XP), the samples were embedded in paraffin (TES, Medite). Sections (2-3 $\mu \mathrm{m}$ thick, microtome Reichert-Jung 2030) were deparaffinised in xylene and haematoxylin and eosin (H\&E) stained or periodic acid Schiff stained according to standard protocols. Blinded evaluation of 24 mice (young: $n=7$; aged: $n=9$; aged $\operatorname{spd}^{+}: n=8$ ) by light microscopy
(Axioskop 40, Zeiss) was performed by a trained pathologist and representative microphotographs were taken (AxioCam MRc, Zeiss).

Histology of tissue sections

The hearts were screened histologically for age-related changes. A longitudinal section through both ventricles was made from the heart base to the apex, presenting the auricles, main and surrounding vessels, aortic valve, mitral valve and in some animals as well the tricuspid valve. Samples were reviewed for signs of cardiomyopathy and endocarditis including arteritis of aorta and surrounding vessels, heart valve inflammation and atrial thrombosis. Gross organ systems were screened for neoplastic changes. For scoring, a semi-quantitative system was used. Specifically, three parameters were scored for alterations of the heart valves and of the aorta: 1, mild inflammatory infiltration; 2 , marked inflammatory infiltration; 3 , severe inflammatory infiltration with thrombus formation. Scores for heart valves and aorta were summarised. Neoplastic changes were reported as yes/no. The presence of a neoplastic change was scored with 1 and quantified separately.

The kidneys were analysed in respect to chronic progressive nephropathy, glomerulonephritis and amyloidosis and each part was scored according to severity $[11,43,68]$. The liver score was based on the frequency of the appearance of (a) lymphatic infiltration of the intrahepatic bile ducts, (b) parenchymla granuloma and (c) necrotising hepatitis $[16,39]$.

Quantitative fluorescence in situ hybridization

Mouse cardiac tissue samples were also used for telomere analysis. Five-micrometre thick sections of paraffin-embedded tissue were cut and deparaffinised in xylene and then rehydrated in serial ethanol concentrations. The slides were washed in PBS for $5 \mathrm{~min}$ and incubated at $37{ }^{\circ} \mathrm{C}$ for $10 \mathrm{~min}$ in acidified pepsin solution ( $1 \mathrm{mg} / \mathrm{ml}$ pepsin, Roth; $0.01 \mathrm{M} \mathrm{HCl}$, Roth). Slides were washed with PBS and fixed with $4 \%$ paraformaldehyde again, and then dehydrated in a $70-100 \%$ ethanol series ( $5 \mathrm{~min}$ each). After $10 \mathrm{~min}$ of air drying, $30 \mu \mathrm{l}$ of telomere probe mix (10 mM Tris $\mathrm{pH} 7.4,25 \mathrm{mM}$ $\mathrm{MgCl}_{2}, 9 \mathrm{mM}$ citric acid, $82 \mathrm{mM} \mathrm{Na} \mathrm{HPO}_{4}, 70 \%$ deionised formamide (Ambion), $0.25 \%$ blocking reagent (Roche) and $0.5 \mu \mathrm{g} / \mathrm{ml}$ Telomeric Cy3 PNA probe (Panagene)) were added to each slide. A coverslip was 
added and then slides were incubated at $85^{\circ} \mathrm{C}$ for $3 \mathrm{~min}$, and further incubated at room temperature for $2 \mathrm{~h}$ in a wet chamber in the dark. After probe incubation, slides were washed $2 \times 15 \mathrm{~min}$ in wash buffer $(10 \mathrm{mM}$ Tris $\mathrm{pH} 7.2$, $0.1 \%$ BSA and $70 \%$ formamide (Roth)) under vigorous shaking $(550 \mathrm{rpm})$, then $3 \times 5 \mathrm{~min}$ in TBS- $0.08 \%$ Tween20, and then incubated with 4',6-diamidino-2phenylindole (DAPI) (Sigma) before mounting samples in Vectashield (Vector ${ }^{\mathrm{TM}}$ ). Confocal images were acquired as z-stacks every $1 \mu \mathrm{m}$ for a total of $5 \mu \mathrm{m}$ using a Zeiss LSM 780 confocal microscope equipped with a $\times 40$ objective. Maximum projections were created using the ZEN software. Telomere signal intensity was quantified using the ImageJ plugin Telometer. Three sections per heart were imaged in a blinded fashion and 40 nuclei were counted for each section resulting in 120 nuclei per animal (young: $n=5$; aged: $n=4$; aged $\operatorname{spd}^{+}: n=4$ ). To digitally reduce noise signals from non-specific qFISH probes, intensity value threshold was set to 25.000 and afterwards data were analysed for outliers using ROUT $(Q=1 \%)$.

Statistical analysis

Statistical analysis was performed using the Prism7 (GraphPad Software) software. Group data were either compared by one-way analysis of variance (ANOVA) followed by Tukey's post hoc test or Kruskal-Wallis with Dunn's comparison for multiple comparisons. Two groups were compared using Mann Whitney test or unpaired 2-sample $t$ test. Values of $p<0.05$ were considered to be significant. If not stated otherwise, data are given as mean \pm standard deviation (SD).

\section{Results}

Spermidine treatment protects against ageing-induced hair loss

In the present study, we investigated the role of spermidine supplementation on different aspects of the ageing process using mice as a model. To this end, we compared three independent cohorts of mice: a non-treated young control group (6 months), non-treated aged (25 months) mice and spermidine-treated aged ( 25 months) mice. The latter had received a 6-month long spermidine supplementation in the drinking water ( $3 \mathrm{mM}$, ad libitum) prior to the first time point of the analysis, starting the supplementation at 18 months of age.
First, comparing the two groups of aged animals revealed no difference in drinking behaviour, suggesting no apparent adverse effects of the administration of spermidine $\left(\operatorname{spd}^{+}\right)$(Fig. 1a). Moreover, both aged groups showed a similar body weight increase relative to starting point of the analysis at 18 months (Fig. 1b), with no significant differences in body weight gained (Fig. 1c). Despite these similarities, we found that aged $\mathrm{spd}^{+}$animals obviously exhibited less hair loss. As shown in Fig. 1d, the spermidine-treated mice appeared to still bear fully covered bodies. In contrast, the control animals showed areas on their back with significantly sparse fur coverage (Fig. 1d). As hair loss is a characteristic feature of advanced ageing in mice [21], we quantified the effects of spermidine treatment for this phenotype. Indeed, quantitative analysis revealed that the fur-uncovered area was significantly decreased upon spermidine treatment (Mann Whitney test, $p=0.041$; Fig. 1e). To exclude effects of barbering in aged animals, mice were separated into single cages at least 3 weeks prior the final experiments.

Spermidine supplementation partly ameliorates age-related changes of brain glucose metabolism

Having observed that spermidine supplementation was effective against age-induced hair-loss, we next analysed whether 6 months of spermidine treatment would also have effects on another age-impaired functional entity - brain glucose metabolism. To investigate the cerebral effect of spermidine, we performed $\left[{ }^{18} \mathrm{~F}\right]$ FDG PET in anaesthetised mice. We analysed three different parameters: (i) glucose uptake, (ii) the brain influx rate constant $K_{\mathrm{i}}$ and (iii) the metabolic rate of glucose uptake $\mathrm{MR}_{\mathrm{Glu}}$. This was done in two different ways of image analysis: first, we used volume of interest (VOI) atlas-based approach, which allows for a comparison of functionally related brain areas within the treatment groups. Second, we used statistical parametric mapping (SPM)-based image analysis, which allows for statistical analysis of group differences at the atlasindependent whole-brain voxel-level.

Analysing glucose uptake, which corresponds to the absolute amount of $\left[{ }^{18} \mathrm{~F}\right] \mathrm{FDG}$ in the brain in a certain time window, both ways of image analysis revealed a higher $\left[{ }^{18} \mathrm{~F}\right] \mathrm{FDG}$ uptake in aged animals compared to young animals in parts of the caudate putamen, thalamic regions and cerebellum (Fig. 2a, b). Such an increase is surprising and maybe a homeostatic counteraction to 

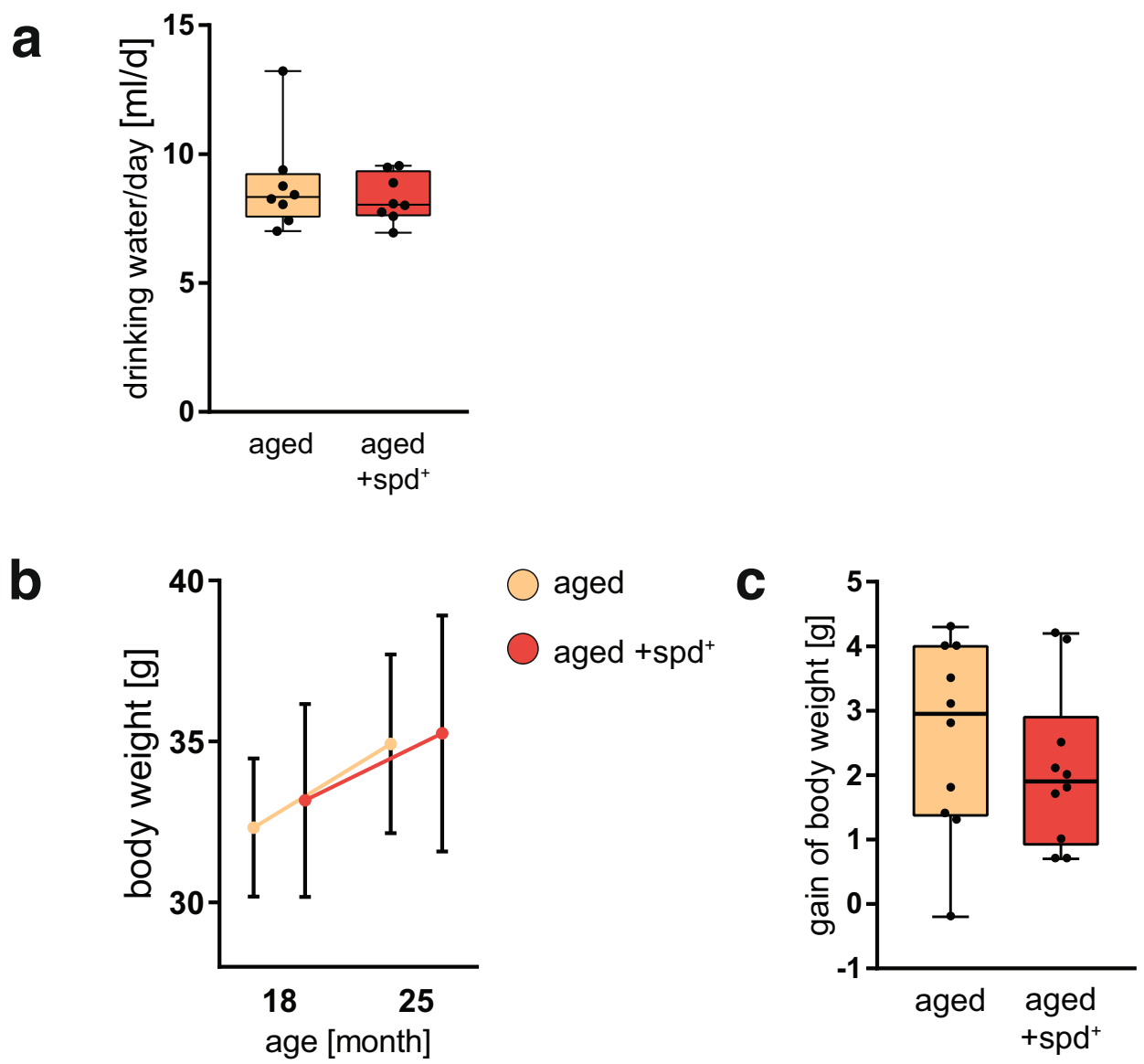

d
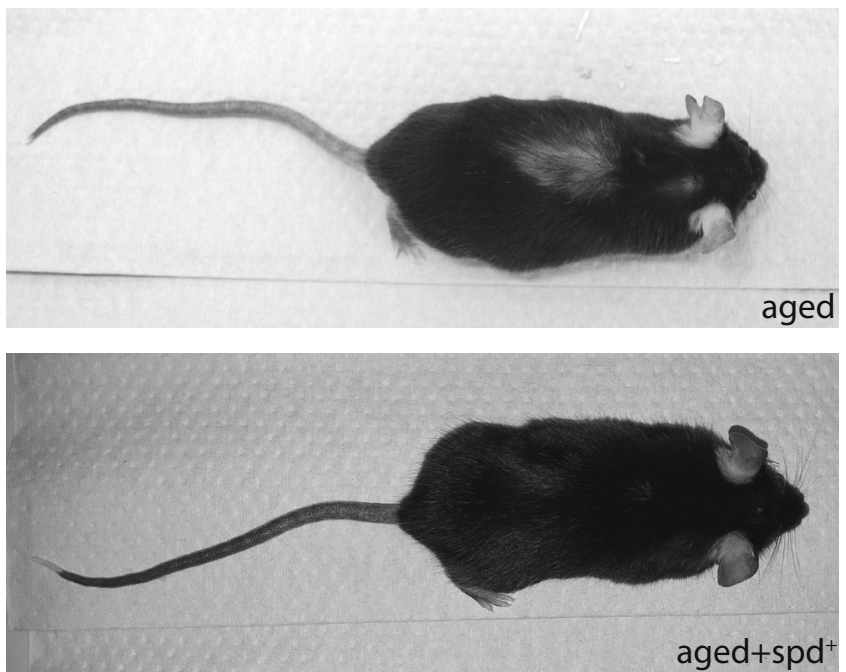

e

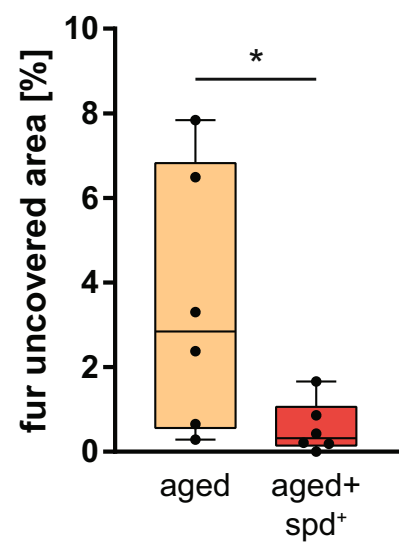

Fig. 1 a Consumption of drinking water in two independent cohorts of mice including non-treated aged (25 months) and spermidine-treated $\left(\mathrm{spd}^{+}\right)$aged (25 months) mice. The latter was undergoing a 6-month long spermidine treatment $(3 \mathrm{mM})$ in the drinking water ad libitum, starting at 18 months of age. Min-to-max box whisker of the mean water intake per day for a single mouse in both groups is shown. $\mathbf{b}$ Changes in the absolute body weight (mean $+\mathrm{SD}$ ) in mice during ageing and treatment. $\mathbf{c}$ Difference in gain of body weight in both aged groups of mice as min-to-max box whisker plot. $N=10$ mice per group. d Representative images of aged and aged $+\mathrm{spd}^{+}$mice at an age of 25 month highlighting the differences in top-side fur coverage in aged animals. e Quantification of the hairless area in percent, depicted as minto-max box whisker plot. $N=6$ mice, Mann Whitney test, $p=0.041$ 
Fig. 2 Coronal and horizontal average $\left[{ }^{18} \mathrm{~F}\right]$ FDG PET parametric brain images of a $\left[{ }^{18} \mathrm{~F}\right]$ FDG uptake ([\% ID/cc $\left.]\right), \mathbf{c}$ influx rate constant $K_{\mathrm{i}}[\mathrm{ml} / \mathrm{g} / \mathrm{min}]$ and $\mathbf{d}$ glucose metabolic rate $\mathrm{MR}_{\mathrm{Glu}}[\mu \mathrm{mol} / \mathrm{min} / 100 \mathrm{~g}]$ calculated using Patlak graphical analysis in 6 month old (young) and in 23 month old untreated (aged) or spermidine-treated $\left(\right.$ aged $+\mathrm{spd}^{+}$) mice. $\mathbf{b}$ Results of voxel-based statistical parametric mapping of $\left[{ }^{18} \mathrm{~F}\right] \mathrm{FDG}$ uptake (unpaired 2-sample $t$ test) identifying differences between young, aged and aged $\mathrm{spd}^{+}$mice. The caudate putamen is indicated by a white arrowhead, thalamic regions by an asterisk. Cerebellum is flanked by two white hexagons. Threshold has been set to show only statistically significant voxels $(p<0.05$; minimum cluster size of 50 voxels). Increases are indicated as hot scale. Additional data are presented in Supplementary Fig. S1
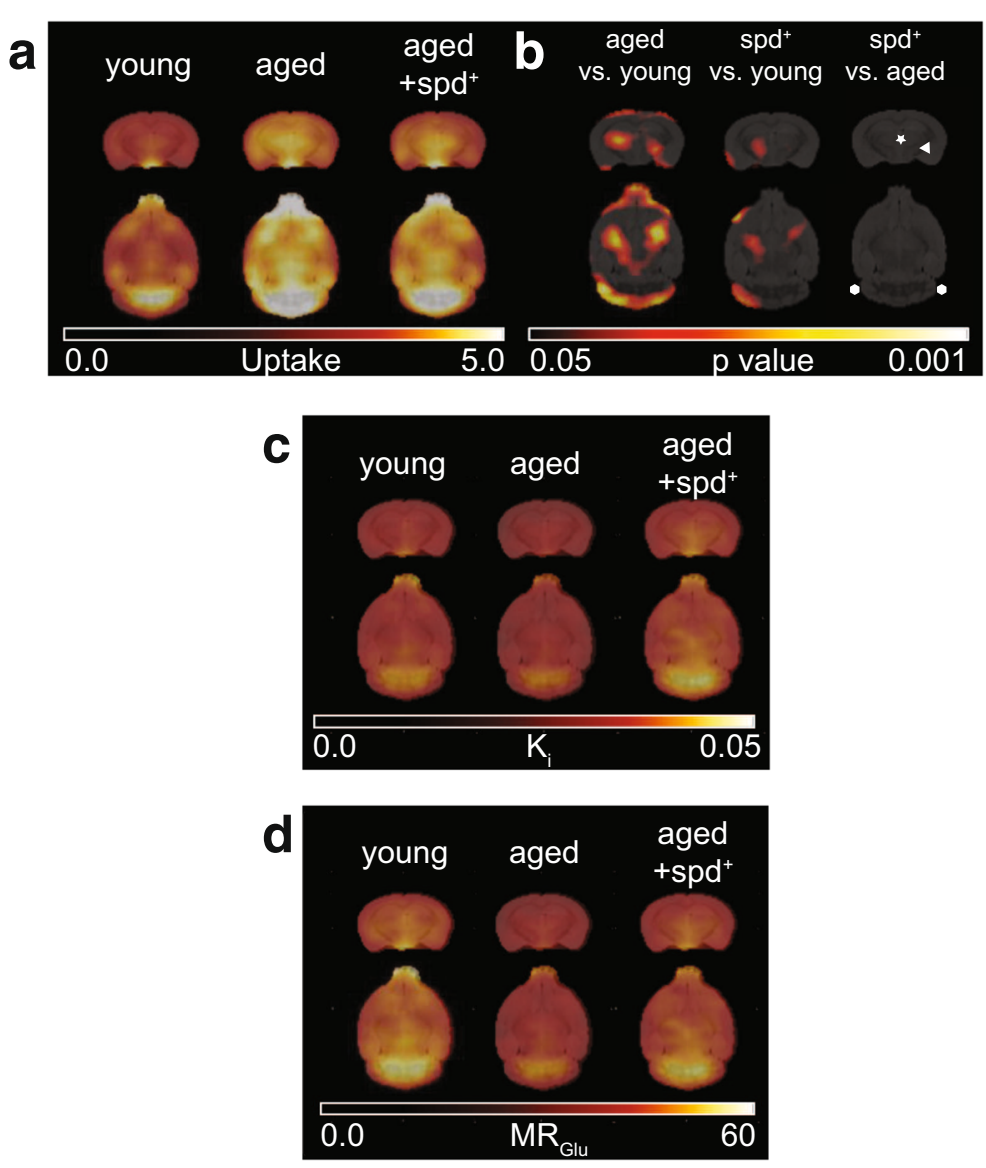

young animals showed higher $\mathrm{MR}_{\mathrm{Glu}}$ in comparison to both aged non-treated and aged $\mathrm{spd}^{+}$groups in various brain regions (Fig. 2d, S1C and S1E), reaching significance for the hypothalamic region (aged vs. young: $p=$ 0.012, aged $+\operatorname{spd}^{+}$vs. young: $p=0.033$ ).

Spermidine treatment ameliorates age-related pathologies in the heart, the kidney and the liver

Ageing is frequently accompanied by cardiac disease (cardiac hypertrophy, myocardial infarction, etc.) leading to declined left ventricular function and ultimately heart failure. Therefore, we next investigated the impact of spermidine on heart function and heart tissue morphology in our aged mouse model. Analysing the left ventricular myocardium with $\left[{ }^{18} \mathrm{~F}\right] \mathrm{FDG}$ PET, we did not obtain any significant changes in $\left[{ }^{18} \mathrm{~F}\right] \mathrm{FDG}$ uptake and in $K_{\mathrm{i}}$ between groups (Fig. $3 \mathrm{a}$ to c). However, $\mathrm{MR}_{\mathrm{Glu}}$ was significantly decreased in both aged groups compared to young animals (aged vs. young: $p=0.0002$, aged $+\operatorname{spd}^{+}$vs. young: $\left.p=0.0004\right)$, whereas no 

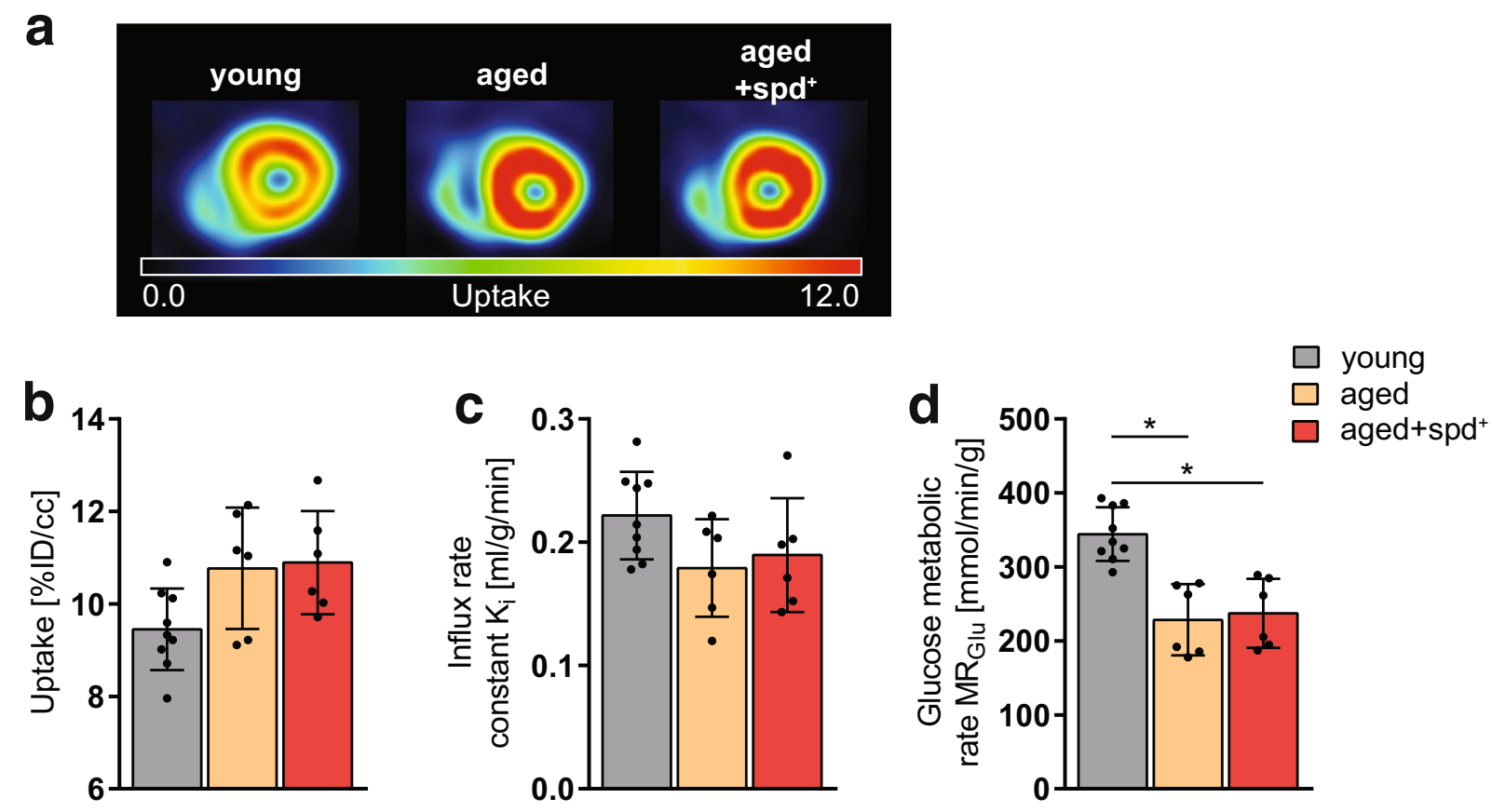

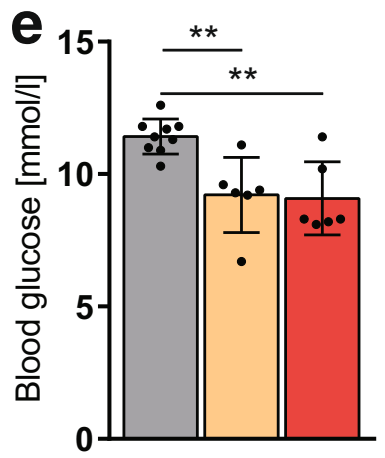

Fig. 3 a Representative transaxial myocardial $\left[{ }^{18}\right.$ F $]$ FDG PET uptake images in 6 month old young and in 23 month old untreated (aged) or spermidine-treated $\left(\right.$ aged $\left.+\mathrm{spd}^{+}\right)$mice. Quantification of b myocardial $\left[{ }^{18} \mathrm{~F}\right] \mathrm{FDG}$ uptake $[\% \mathrm{ID} / \mathrm{cc}]$, c influx rate constant $K_{\mathrm{i}}$ $[\mathrm{ml} / \mathrm{g} / \mathrm{min}]$ and d glucose metabolic rate $\mathrm{MR}_{\mathrm{Glu}}[\mu \mathrm{mol} / \mathrm{min} / 100 \mathrm{~g}]$

difference between the two aged groups could be observed (Fig. 3d). While blood glucose values did not differ between aged and aged $\mathrm{spd}^{+}$mice (Fig. 3e), young animals had significantly higher blood glucose levels (measurements before the $\left[{ }^{18} \mathrm{~F}\right] \mathrm{FDG}$ PET/CT scan) than either aged non-treated $(p=0.003)$ or aged $\mathrm{spd}^{+}$mice $(p=0.005)$. These data suggest that an age-induced decrease in general glucose metabolism is not responsive to spermidine supplementation.

Having performed non-invasive molecular heart imaging, we then addressed the possible role of spermidine in the left ventricular myocardium. e Blood glucose levels $[\mathrm{mmol} / \mathrm{l}]$, measured prior to the PET scan. Significant differences calculated by one-way ANOVA and Tukey's post hoc test comparing all groups with each other are indicated by asterisk $(p<0.05)$

in preventing age-induced histological abnormalities within aged hearts (Fig. 4a). In this study, we mainly focused on inflammatory cardiac lesions, since lesions like calcification or myocardial infarction were not observed in any animal. As shown in Fig. 4b, the young control group showed no signs of age-related histopathology. Quantification of a histo-pathological/inflammatory score retrieved a significant increase in the aged non-treated and aged $\mathrm{spd}^{+}$groups when compared to the young mice (Kruskal-Wallis test $p=0.010$ and $p=0.039$ respectively, Fig. $4 b$ ). To better visualize the 
effects of spermidine supplementation in ageing hearts, Fig. $4 \mathrm{c}$ shows the histogram of individual scores for different experimental groups (Fig. 4c). This histogram indicates that within the spermidine treated group, $8.3 \%$ of the mice suffered from severe inflammatory changes within the heart compared to $26.7 \%$ in the aged control group. Furthermore, in the treated group, $66.7 \%$ of the animals showed mild signs of inflammation, whereas in the aged control group only $40 \%$ showed mild changes, supporting a general beneficial effect of spermidine on the ageing heart.

Of note, none of the young mice showed neoplastic changes, whereas in $44 \%$ of the aged non-treated mice neoplastic changes occurred. In the aged $\mathrm{spd}^{+}$mice, a similar number $(37.5 \%)$ showed neoplastic changes, suggesting that spermidine treatment did not influence the occurrence of neoplasia.

In addition, we performed a histo-pathological analysis of the liver and the kidney using literature-based scores to quantify the severity of pathological changes. Within the liver, we recognised granuloma within the parenchyma in all groups as well as infiltrations within the bile duct to a similar extend ([65] and Fig. S2). Aged control and spermidine treated animals showed $33.3 \%$ and $37.5 \%$ severe pathological changes in the liver, respectively. Notably, however, necrotic changes within the liver were obtained only within the control aged group (11.1\%), but not in the spermidine-treated one. Moreover, the percentage of animals with mild pathological changes was higher in the spermidine-treated group $(62.5 \%$ vs. $55.6 \%)$.

In the kidney, we observed chronic nephropathy with few foci of basophilic tubules, no or mild interstitial mononuclear accumulation and some proteinaceous casts within both aged groups (Fig. S3). Furthermore, aged animals showed signs of a glomerulonephritis with some glomeruli affected by hypertrophy and hyperplasia of mesangial cells and dilatation of glomerular urinary space. Detailed histological analysis revealed that only $12.5 \%$ of spermidine treated animals show severe pathological changes compared to $33.3 \%$ in the aged group. At the same time, spermidine treatment increased the percentage of mildly affected animals up to $87.5 \%$, while $66.7 \%$ of the aged control animals were mildly affected.

Spermidine treatment protects against telomeres shortening in cardiac tissue

To test whether cardioprotective effects of spermidine were also associated with a modulation of telomere length in cardiac tissue, we applied quantitative fluorescence in situ hybridization (qFISH) to assess the relative telomere length in heart tissue sections [7].

Frequency distribution analysis of the telomere length of at least 4.400 individual telomere signals per group revealed an expected shift to shorter telomeres in nontreated old animals in comparison to young mice (Fig. 5a). Intriguingly, a similar distribution was obtained when non-treated aged (more short telomeres) and aged $\mathrm{spd}^{+}$ (less short telomeres) groups were compared (Fig. 5b). Importantly, however, this ageing-related shift was absent when young and old spermidine-treated mice were compared (Fig. 5c). These differences are further underpinned by quantifying Spearman correlation coefficients for the different groups, which highlights the similarity between young and spermidine-treated groups ( $R=1$ vs. $R=0.97$ for young vs. aged control) with regard to their telomere length distribution (Table 1).

It is well documented that the percentage of short telomeres per cell is particularly associated with ageing and age-related pathologies including those of the heart $[3,61]$. Thus, we determined the incidence of short telomeres for individual animals in the different experimental groups. Telomeres were defined as short if their signals were below $50 \%$ of the mean telomere length/ nucleus value (defined individually for each animal). Strikingly, this analysis revealed that spermidine treatment provoked a significantly decreased percentage of nuclei with short telomeres in comparison to untreated aged animals $\left(0.4 \% \pm 0.47 \%\right.$ in aged $\mathrm{spd}^{+}$vs. $9.1 \% \pm$ $7.63 \%$ in aged control; Kruskal Wallis test, $p=0.033$, Fig. $5 d$ ). In addition, image analysis clearly demonstrated that nuclei of cardiac cells from young and aged $\mathrm{spd}^{+}$ animals contained more qFISH spots of high fluorescence intensity than nuclei from control old animals (Fig. 6a). These results were further corroborated by analysing the number of detectable telomere signals per nucleus. Here, numbers were significantly lower in aged controls when compared to aged $\mathrm{spd}^{+}$mice, indicating that more telomeres had shortened below the detection limit in the aged mice under our specific experimental settings (Kruskal Wallis test, $p=0.033$, Fig. $6 \mathrm{~b}$ ).

\section{Discussion}

Spermidine supplementation previously has been shown to promote lifespan extension, although underlying mechanisms are not completely understood [34]. 


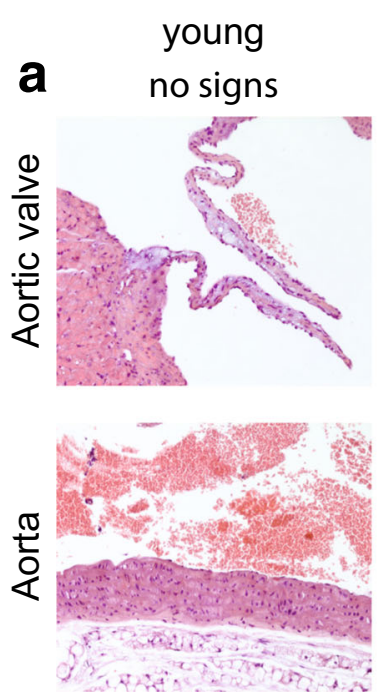

aged

strong signs
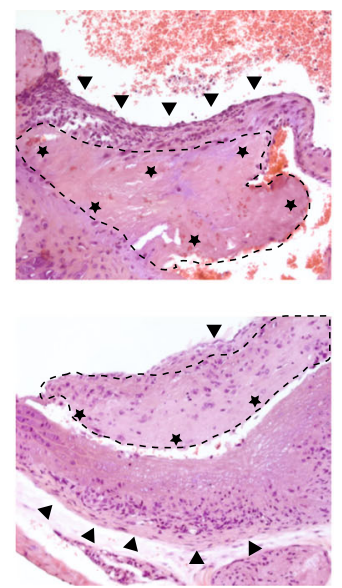

aged + spd $^{+}$

small signs
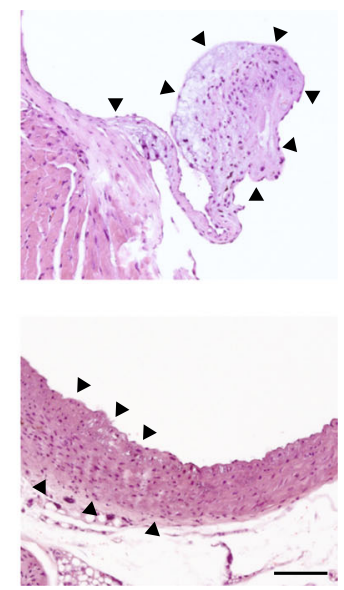

scheme
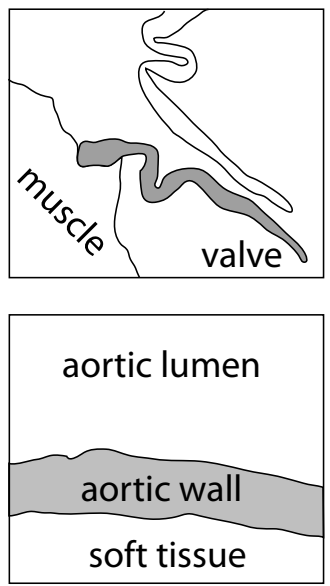

b

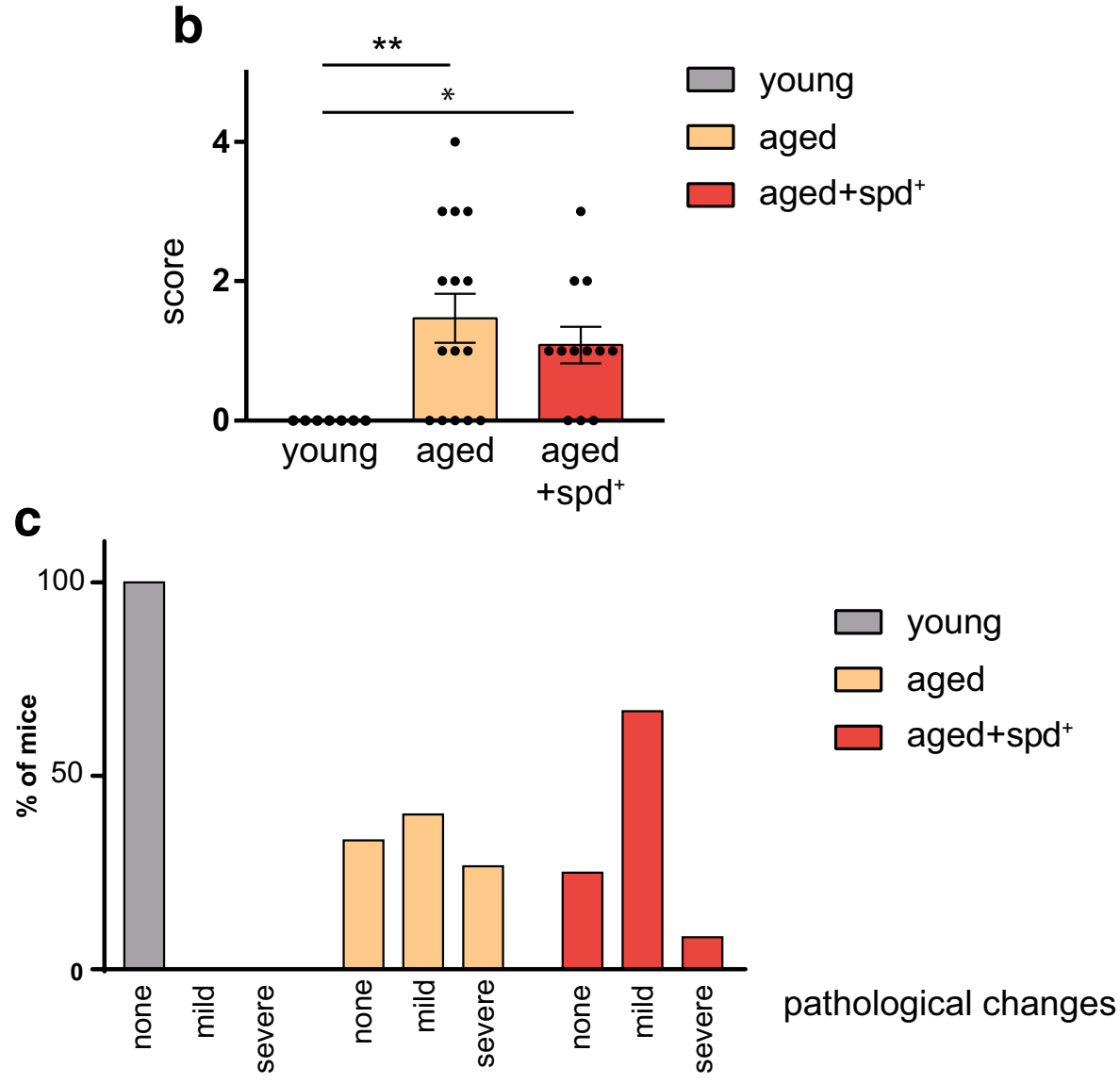

C

As ageing has multiple mechanistic dimensions, we investigated an extended spectrum of age-associated phenotypes in the present study. To this end, we compared young, normally aged and late-in-life spermidine supplemented aged wild-type mice in respect to several, translationally relevant age-related alterations.

By phenotypic analysis, we noticed that the ageingrelated hair loss was decreased upon the long-term 
Fig. 4 a Representative haematoxylin/eosin stainings of the histological heart samples. Upper panel illustrates pathophysiological changes within the aortic valve across all groups. The lower panels highlight the severity of different age-related changes within the aorta. Arrowheads point to tissue infiltration of macrophages characteristic for inflammation and tissue degeneration, whereas asterisks mark thrombus (dashed line) built-up within the aorta. Scale bar $100 \mu \mathrm{m}$. The scheme on the right illustrates anatomical structures analysed. Grey part undergoes pathological changes in aged mice and is shown in all images. b The pathological score (heart) as mean \pm SEM. Kruskal-Wallis test with Dunn's multiple comparison, adjusted $p^{* *}=0.010 ; p^{*}=0.039 . N=7$ for young control, $N=15$ for aged non-treated animals and $N=12$ for spdtreated mice. c Histogram showing percentage of mice carrying none, mild or severe pathological heart changes

spermidine supplementation, suggesting a protective role of spermidine against hair loss (alopecia) in aged mice. Interestingly, these data are in line with in vitro findings that spermidine may promote human hair growth [47] and with clinical trial data indicating that spermidine supplementation may be beneficial against human hair loss [49]. These results further indicate that the spermidine supplementation per se was effective against age-induced deteriorations. Of note, in mice, denudation of special parts of the body can also be linked to a behavioural phenotype called barbering. It based on the interaction of a barber animal and a recipient in which the barber nibbles whiskers and fur of the recipient for various reasons [22]. To avoid a barbering, we separated mice into single cages at least 3 weeks prior to the final experiments. This time period should be enough for the fur regrowth [52], and thus, we think barbering does not play a role in the observed fur loss.

One possible reason for preserved fur growth in $\mathrm{spd}^{+}$ animals could be a spermidine-mediated induction of autophagy, which was documented across a wide spectrum of experimental models $[18,33,36]$. Indeed, previously, it was shown that quiescent hair follicles can be stimulated to initiate hair growth in mice by feeding small molecules activating autophagy, including $\alpha$ ketoglutarate $(\alpha-\mathrm{KG})$ and $\alpha$-ketobutyrate $(\alpha-\mathrm{KB})$ [8]. This is in line with the previous observation that supplementation of $\alpha$-KB in old mice can prevent alopecia, which refers partial hair loss from head or body. A mechanistic link between autophagy and hair regeneration was further supported by the fact that stimulation of hair growth by $\alpha-\mathrm{KG}$ and $\alpha-\mathrm{KB}$ was blocked by specific autophagy inhibitors [8].

Alopecia is very common in human ageing [60]. Even tough not experimentally tested yet, one could thus speculate that dietary spermidine might increase hair growth in humans as well. Indeed, first evidence in this direction was obtained for human ex vivo hair follicle cultures, in which the spermidine-induced growth was shown to be autophagy-dependent [42]. Consistently, caloric restriction was shown to promote hair follicle growth as well, although the molecular mechanisms were not investigated in detail [17]. Since spermidine not only is an inducer of autophagy [44] but also has features of a caloric restriction mimetic [35], it could be interesting to explicitly test the protective potential of spermidine supplementation towards age-induced alopecia in future preclinical and clinical studies.

Of note, the spermidine-treated animals showed no increase in neoplastic changes compared to the aged non-treated animals, confirming that the prolonged supplementation with spermidine is safe in terms of neoplasia induction. This might be linked to spermidinetriggered depletion of regulatory T-cells [45]. This finding is also in line with our recent observations from a tolerability study which demonstrated that spermidine is well tolerated and does not increase morbidities or change behaviour in BALBc/Rj mice [53]. Furthermore, this study along others [12] showed that even though spermidine is proposed to harbour caloric restriction mimicking properties, food consumption usually does not change with the treatment, neither in young, nor in aged mice.

$\left[{ }^{18} \mathrm{~F}\right]$ FDG PET was used to obtain novel information about spermidine effects on brain glucose metabolism. $\left[{ }^{18} \mathrm{~F}\right]$ FDG PET is one of the commonly used noninvasive approaches to study functional decline in the ageing brain, with $\left[{ }^{18} \mathrm{~F}\right] \mathrm{FDG}$ as the most popular radiotracer for analysis of cerebral glucose uptake [6]. Particularly, neurodegenerative diseases are often accompanied with gluco-metabolic changes. While atlas-based uptake analysis did not result in significant changes, the statistical parametric mapping (SPM) approach, which allows for statistical comparison between the experimental groups, revealed that $\left[{ }^{18} \mathrm{~F}\right] \mathrm{FDG}$ uptake is significantly increased in caudate putamen, thalamus and cerebellum of aged animals when compared to young mice. Of note, this age-induced increase was less prominent in the aged $+\mathrm{spd}^{+}$group. The reduced glucose uptake observed in young animals could be explained by the fact that $\left[{ }^{18} \mathrm{~F}\right] \mathrm{FDG}$, which was administered in tracer dosage, is competing with endogenous blood glucose for brain uptake, with young mice being known 

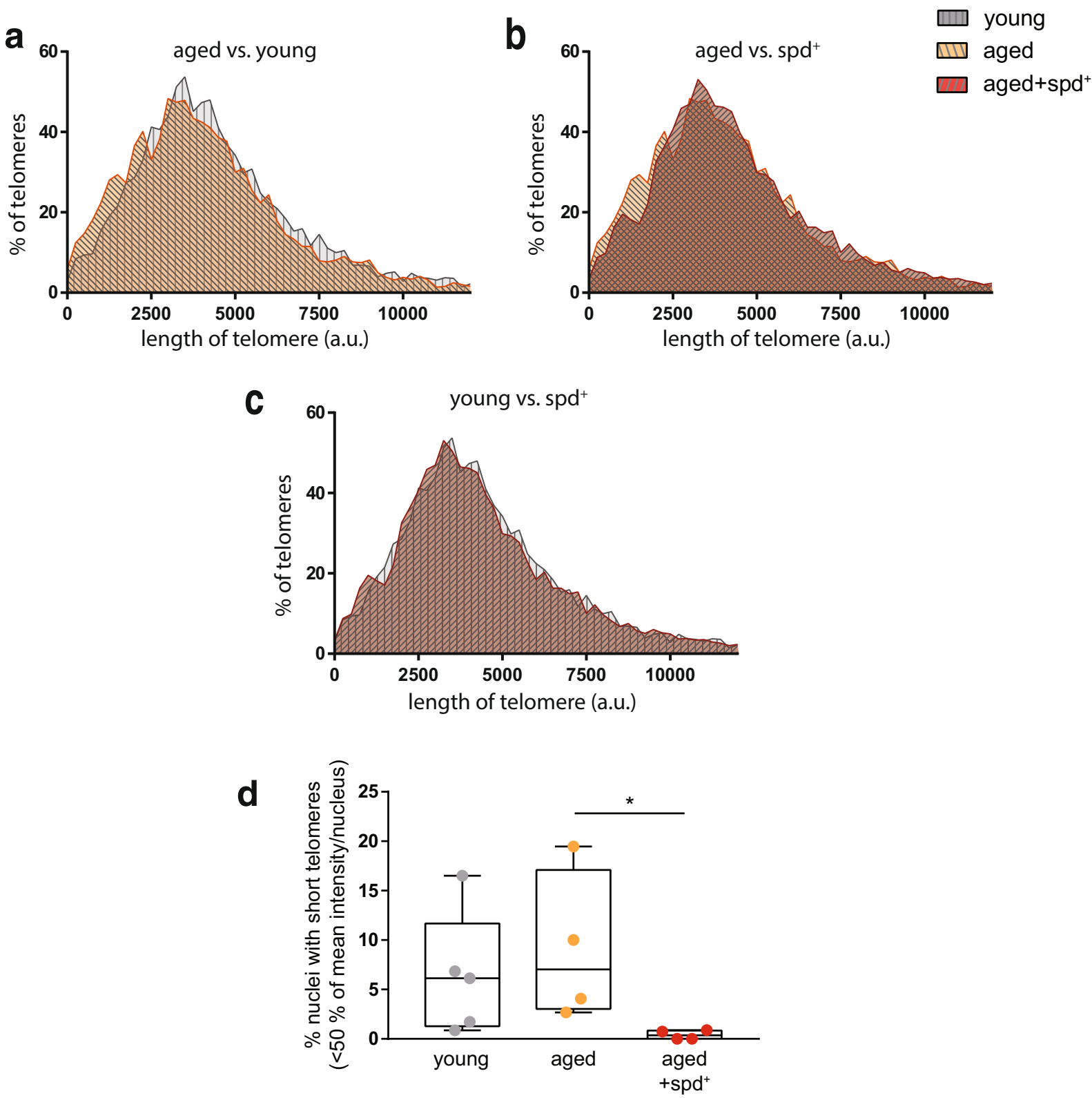

Fig. 5 Comparison of the frequency distribution histograms of the telomere length between a non-treated aged mice and young mice, b non-treated aged and aged $+\mathrm{spd}^{+}$mice and $\mathbf{c}$ aged $+\mathrm{spd}^{+}$mice and young mice. At least 4.400 individual telomere signals per group were evaluated. d Quantification of the nuclei with short

to have higher blood glucose levels than old animals [28], as also confirmed in the present study.

In contrast to sole uptake analysis, kinetic modelling describes the dynamic tissue uptake relative to the plasma activity by measuring rate constants and therefore allows calculating values describing glucose turnover, an entity coupled with synaptic activity. Voxel-based telomeres. Min-to-max box whisker plot is shown. Telomeres were defined as short, if their signals were below $50 \%$ of the mean telomere value of the same mouse. Each mouse is represented as a single dot in the plot. Kruskal-Wallis test with Dunn's multiple comparison, adjusted $p=0.033$

average $\mathrm{MR}_{\mathrm{Glu}}$ and $K_{\mathrm{i}}$ maps hint towards lower values in aged control mice but preserved or increased values in spermidine-treated animals compared to young mice. Accordingly, SPM analysis of $K_{\mathrm{i}}$ maps revealed significant regional differences between spermidine-treated vs. non-treated aged mice in cortical, thalamic and cerebellar brain tissue. SPM analysis of $\mathrm{MR}_{\mathrm{Glu}}$ maps also 
Table 1 Spearman correlation coefficient between different groups highlighting the similarity between young and spermidine-treated groups with regard to telomere length distribution

\begin{tabular}{lll}
\hline Spearman coefficient $[R]$ & & $p$ value \\
\hline Young vs. control & 0.97 & $1.48 \cdot 10^{-7}$ \\
Young vs. spd $^{+}$ & 1.00 & $4.59 \cdot 10^{-11}$ \\
spd $^{+}$vs. control & 0.97 & $1.97 \cdot 10^{-7}$ \\
\hline
\end{tabular}

displayed an age-dependent decrease in various brain regions, reaching significance in the hypothalamus. These finding underline the importance of performing kinetic modelling as sole uptake analysis without taking blood glucose into account can be misleading. As already mentioned, the metabolic rate of glucose consumption $\mathrm{MR}_{\mathrm{Glu}}$ can be a measure reflecting synaptic activity. During physiological ageing, not all brain areas are affected to a similar extent. Indeed, there are hot spots of ageing within the brain with decline typically starting in thalamic areas [57]. Another brain region that a
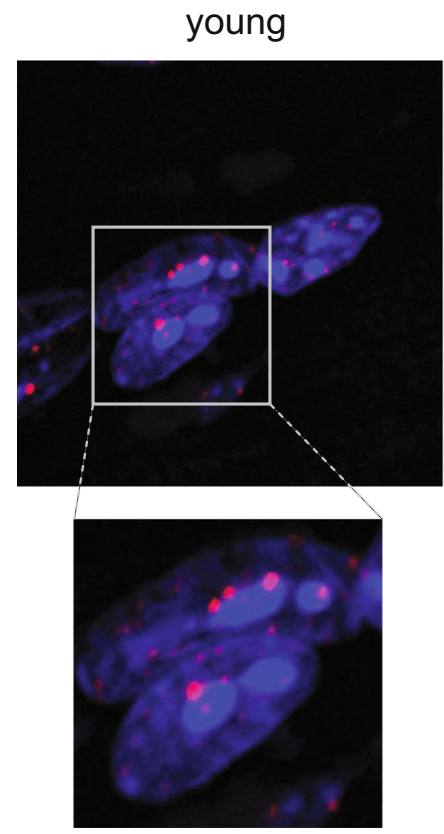
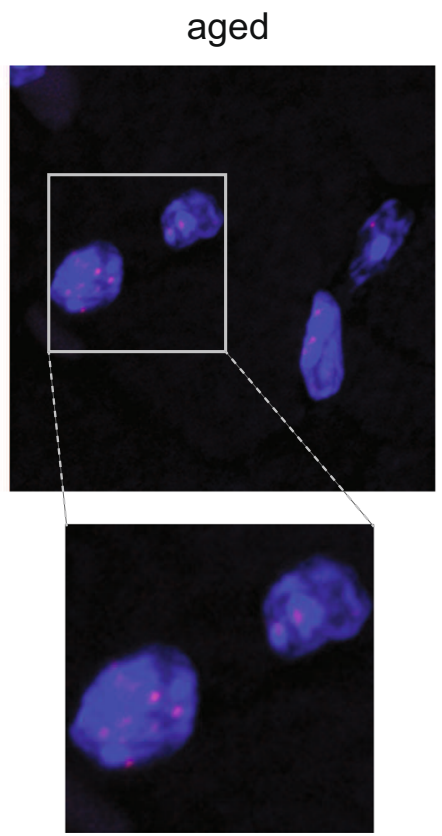
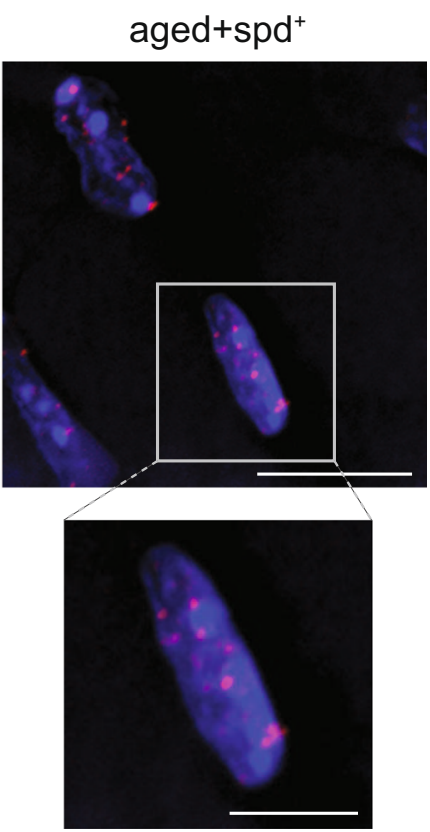

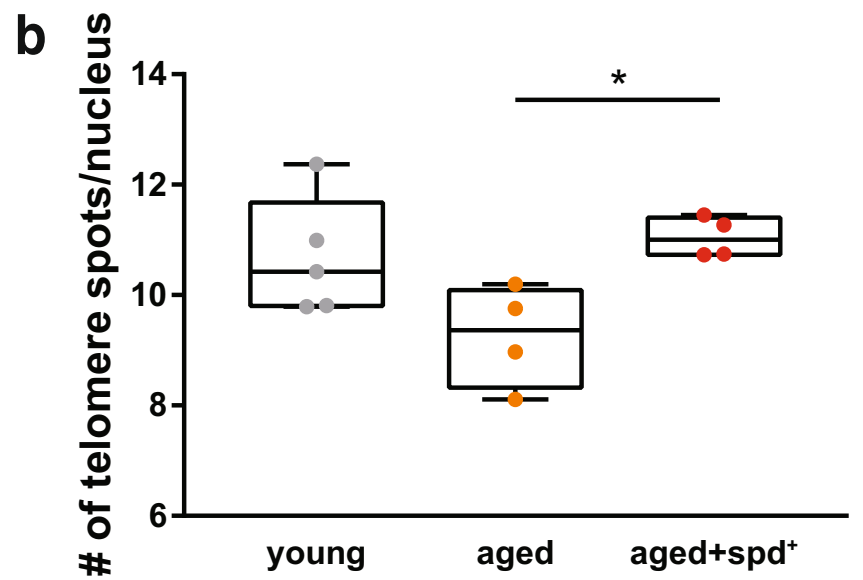

Fig. 6 a Representative qFISH staining of paraffin heart sections for all three conditions. Telomeres were stained with $\mathrm{Cy} 3$ (red), and nuclei with DAPI (blue). Scale bar $10 \mu \mathrm{m}$ (inset $5 \mu \mathrm{m}$ ). b
Quantitative analysis of the number of detectable telomere signals per nucleus ( $n \leq 120$ nuclei/mouse). Kruskal-Wallis test with Dunn's multiple comparison, adjusted $p=0.033$ 
is strongly affected during ageing is the hypothalamus [25]. Our PET analysis revealed ageing-related decrease in the metabolic rate within these brain areas in nontreated age mice, while spermidine supplementation seems to be protective against such changes. Among several pathways affected by spermidine, the observed changes might be explained by an improved mitochondrial function in these brain areas and by modulation of the synaptic vesicle pool [36].

Ageing is undoubtedly linked to inflammatory processes, which also cause many comorbidities. This scenario referred to as 'inflamm-ageing' plays a crucial role in the development of cardiovascular diseases [29]. In the present study, we found severe tissue inflammation within aortic valves and aortas in aged control animals, but not in the heart tissues of young mice. More importantly, these pathological changes were ameliorated upon spermidine supplementation, suggesting that spermidine possesses an anti-inflammatory effect [26]. Notably, previous analysis using a similar study design showed that spermidine supplementation reduced plasma TNF- $\alpha$, and could thus contribute to a decrease of inflammation in heart tissue [12]. Furthermore, spermidine might improve cardiac health by facilitating mitochondrial biogenesis [64]. It is also noteworthy that our results suggest protective actions of spermidine in other organs as well, including the liver and the kidney. Consequently, this calls for future extended mouse studies in various ageing tissue types.

To investigate molecular details of spermidine action on cardiac tissue, we addressed the effects of ageing and spermidine interventions in respect to telomere length. Age-induced changes on molecular levels include accelerated telomere shortening, which was described across species borders, including mice and humans [61]. Telomere length represents a well-established biomarker to score the degree of age-induced deterioration, also for the cardiovascular system [14]. Consequently, preservation of telomere length by means of cardiac telomerase gene therapy was shown to confer cardioprotection in aged mice [4]. Importantly, it was previously demonstrated that supplementation of spermidine reduces cardiac hypertrophy and preserves diastolic function in aged mice [12], which is also supported by our own data. The length of telomeres in cardiomyocytes is basically not determined by cell division [9], but still undergoes pronounced shortening during ageing [58]. Our data clearly demonstrate that even when applied late-in-life (months 18 to 24), spermidine treatment was able to rescue age-related telomere shortening to levels comparable of young mice. Importantly, in our study, late-in-life spermidine supplementation could clearly decrease the amount of nuclei with short telomeres in cardiac tissues, known to be critical factors and indicators of cellular senescence and the development of cardiac pathologies [67]. The mechanisms by which spermidine supplementation might lead to less telomere attrition remains elusive at this point. Polyamines are known to play a crucial role in DNA stabilisation and might support G-quadrupole telomere in DNA structures [55], potentially interfering with telomere shortening. In addition, caloric restriction has been linked to attenuated telomere erosion in mice [62]. Recent research supports a beneficial effect of long telomeres, which go along with slowed metabolic ageing [41].

Another intriguing mechanism might involve spermidine-mediated protection of telomeres from oxidative stress. It has been widely documented that age-related increase in cardiac diseases is accompanied by increased level of oxidative stress mediated by reactive oxygen species (ROS), such as free radicals, oxygen ions and peroxides $[10,50]$. Indeed, ROS are considered as a risk factor for a wide range of cardiac diseases in elderly [5], although underlying molecular mechanisms are not yet completely understood. In vitro studies show that telomeric DNA is more susceptible to cleavage by ROS than non-telomeric sequences [63]. Moreover, oxidative stress inhibits telomerase function in vivo, leading to the facilitation of direct ROS-damaging effect on telomeres [1]. On the other hand, natural polyamines, including spermidine, have long been known to act as free radical scavengers [19] and thus protect DNA against oxidative damages $[24,48]$. In addition to the direct effects of polyamines on ROS, they stimulate the expression of proteins essential to an effective antioxidant response, including superoxide dismutases, glutathione and catalases [51]. Therefore, increased amounts of longer telomeres obtained in $\mathrm{spd}^{+}$aged animals might also be explained by the spermidine-mediated reduction of ROS. Whether spermidine partially acts on healthy lifespan expansion by affecting telomerase activity or directly protecting telomeres from attrition by e.g. affecting mitochondrial dysfunction strongly warrants further investigation.

\section{Conclusions}

Spermidine is an endogenous natural substance, whose concentration declines with age and whose systemic 
availability can be enhanced by both nutritional regimes and supplements. Our study links cardio-protective effects of spermidine at the histological level with decreased telomere attrition in heart tissue. In addition, spermidine might modulate age-related changes of brain glucose metabolism and ameliorate number of pathological sights in kidney and liver. Since late-in-life external administration of spermidine protects against many age-associated maladies and seems safe in humans, clinical trials may investigate the possibility of its use as an age-protective strategy.

Supplementary Information The online version contains supplementary material available at https://doi.org/10.1007/s11357020-00310-0.

Authors' contributions Alexander Wirth: conceptualization, methodology, experiments, data evaluation and curation, writing - original draft preparation and editing. Bettina Wolf: methodology, performed experiments, data evaluation and curation. Cheng-Kai Huang: experiments. Sebastian J. Hofer: data evaluation and curation. Silke Glage: experiments and histology. Marion Bankstahl: data evaluation and curation and draft editing. Christian Bär: supervision, data evaluation and curation and funding. Thomas Thum: conceptualization, funding and draft editing. Kai G. Kahl: conceptualization, funding and draft editing. Stephan J. Sigrist: conceptualization, funding and draft editing. Frank Madeo: conceptualization and draft editing. Jens P. Bankstahl: conceptualization, methodology, supervision, data evaluation and curation, draft editing and funding. Evgeni Ponimaskin: conceptualization, methodology, funding, supervision and draft editing.

Funding Open Access funding enabled and organized by Projekt DEAL. This work was supported by the Federal Ministry of Education and Research (BMBF) by the SMARTAGE project to EP, AW and SJS. EP was supported through DFG grant PO732. FM is grateful to the Austrian Science Fund FWF (SFB LIPOTOX F3007 \& F3012, W1226, P29203, P29262, P27893, P 31727), the Austrian Federal Ministry of Education, Science and Research and the University of Graz for grants "Unkonventionelle ForschungInterFast" and "flysleep" (BMWFW-80.109/0001-WF/V/3b/ 2015), as well as the field of excellence program BioHealth. KGK was supported by internal MHH funding. We acknowledge support from NAWI Graz, the BioTechMed-Graz flagship project "EPIAge" and of the field of excellence BioHealth. TT was supported by the ERANET-CVD EXPERT network (BMBF 01KL1711) and the KFO311 (DFG TH903/20). CB was supported through DFG grant BA5631/2.Data availabilityThe data that support the findings of this study are available from the corresponding author upon reasonable request.

\section{Compliance with ethical standards}

Conflict of interest FM and SJS have equity interest in TLL The Longevity Labs. TT is founder and shareholder of Cardior
Pharmaceuticals GmbH. All other authors declare that they have no conflict of interest.

Ethics approval Husbandry and procedures involving animals were carried out according to the German Animal Welfare Legislation as set forth by the European Convention for the Protection of Vertebrate Animals used for Experimental and Other Scientific Purposes, Council of Europe, ETS no.123, appendix VIII and according to national regulations and standards. All experiments were approved by the local Institutional Animal Care and Research Advisory Committee and by the local government, namely the Lower Saxony State Ministry of Food, Agriculture and Consumer Protection in consultation with the Animal Protection Committee with the approval ID: 33.12-42502-04-16/2206.

Consent to participate All authors agree to participate in this study and are involved according to the author contribution.

Consent for publication All authors agree with a publication in Geroscience Journal.

Code availability Not applicable

Open Access This article is licensed under a Creative Commons Attribution 4.0 International License, which permits use, sharing, adaptation, distribution and reproduction in any medium or format, as long as you give appropriate credit to the original author(s) and the source, provide a link to the Creative Commons licence, and indicate if changes were made. The images or other third party material in this article are included in the article's Creative Commons licence, unless indicated otherwise in a credit line to the material. If material is not included in the article's Creative Commons licence and your intended use is not permitted by statutory regulation or exceeds the permitted use, you will need to obtain permission directly from the copyright holder. To view a copy of this licence, visit http://creativecommons.org/licenses/by/4.0/.

\section{References}

1. Ahmed W, Lingner J. PRDX1 and MTH1 cooperate to prevent ROS-mediated inhibition of telomerase. Genes Dev. 2018;32:658-69. https://doi.org/10.1101 /gad.313460.118.

2. Alzheimer's Association. 2016 Alzheimer's disease facts and figures. Alzheimers Dement. 2016;12:459-509. https://doi.org/10.1016/j.jalz.2016.03.001.

3. Bär C, Blasco MA. Telomeres and Telomerase as Therapeutic Targets to Prevent and Treat Age-Related Diseases. F1000Research. 2016. https://doi.org/10.12688 /f1000research.7020.1.

4. Bär C, de Jesus BB, Serrano R, Tejera A, Ayuso E, Jimenez $\mathrm{V}$, et al. Telomerase expression confers cardioprotection in the adult mouse heart after acute myocardial infarction. Nat 
Commun. 2014;5:1-14. https://doi.org/10.1038 /ncomms6863.

5. Butler J, Kalogeropoulos A, Georgiopoulou V, Belue R, Rodondi N, Garcia M, et al. Incident heart failure prediction in the elderly: the health $\mathrm{ABC}$ heart failure score. Circ Heart Fail. 2008;1:125-33. https://doi.org/10.1161 /CIRCHEARTFAILURE.108.768457.

6. Byun MS, Kim HJ, Yi D, Choi HJ, Baek H, Lee JH, et al. Region-specific association between basal blood insulin and cerebral glucose metabolism in older adults. NeuroImage Clin. 2019;22:101765. https://doi.org/10.1016/j. nicl.2019.101765.

7. Canela A, Vera E, Klatt P, Blasco MA. High-throughput telomere length quantification by FISH and its application to human population studies. Proc Natl Acad Sci U S A. $2007 ; 104: 5300-5$. https://doi.org/10.1073 /pnas.0609367104.

8. Chai M, Jiang M, Vergnes L, Fu X, de Barros SC, Doan NB, et al. Stimulation of hair growth by small molecules that activate autophagy. Cell Rep. 2019;27:3413-3421.e3. https://doi.org/10.1016/j.celrep.2019.05.070.

9. Chang ACY, Blau HM. Short telomeres - a hallmark of heritable cardiomyopathies. Differentiation. 2018;100:31-6. https://doi.org/10.1016/j.diff.2018.02.001.

10. Csányi G, Miller FJ Jr. Oxidative stress in cardiovascular disease. Int J Mol Sci. 2014;15:6002-8. https://doi. org/10.3390/ijms15046002.

11. Denic A, Glassock RJ, Rule AD. Structural and functional changes with the aging kidney. Adv Chronic Kidney Dis. 2016;23:19-28. https://doi.org/10.1053/j.ackd.2015.08.004.

12. Eisenberg T, Abdellatif M, Schroeder S, Primessnig U, Stekovic S, Pendl T, et al. Cardioprotection and lifespan extension by the natural polyamine spermidine. Nat Med. 2016;22:1428-38. https://doi.org/10.1038/nm.4222.

13. Eisenberg T, Knauer H, Schauer A, Büttner S, Ruckenstuhl C, Carmona-Gutierrez D, et al. Induction of autophagy by spermidine promotes longevity. Nat Cell Biol. 2009;11: 1305-14. https://doi.org/10.1038/ncb1975.

14. Fasching CL. Telomere length measurement as a clinical biomarker of aging and disease. Crit Rev Clin Lab Sci. 2018;55:443-65. https://doi.org/10.1080 $/ 10408363.2018 .1504274$

15. Faul F, Erdfelder E, Lang A-G, Buchner A. G*Power 3: a flexible statistical power analysis program for the social, behavioral, and biomedical sciences. Behav Res Methods. 2007;39:175-91. https://doi.org/10.3758/BF03193146.

16. Filfan M, Olaru A, Udristoiu I, Margaritescu C, Petcu E, Hermann DM, et al. Long-term treatment with spermidine increases health span of middle-aged Sprague-Dawley male rats. GeroScience. 2020;42:937-49. https://doi.org/10.1007 /s11357-020-00173-5.

17. Forni MF, Peloggia J, Braga TT, Chinchilla JEO, Shinohara J, Navas CA, et al. Caloric restriction promotes structural and metabolic changes in the skin. Cell Rep. 2017;20:267892. https://doi.org/10.1016/j.celrep.2017.08.052.

18. Gupta VK, Pech U, Bhukel A, Fulterer A, Ender A, Mauermann SF, et al. Spermidine suppresses ageassociated memory impairment by preventing adverse increase of presynaptic active zone size and release. PLoS Biol. 2016;14:e1002563. https://doi.org/10.1371/journal. pbio. 1002563 .
19. Ha HC, Sirisoma NS, Kuppusamy P, Zweier JL, Woster PM, Casero RA. The natural polyamine spermine functions directly as a free radical scavenger. Proc Natl Acad Sci U S A. 1998;95:11140-5. https://doi.org/10.1073 /pnas.95.19.11140.

20. Hansen M, Kennedy BK. Does longer lifespan mean longer healthspan? Trends Cell Biol. 2016;26:565-8. https://doi. org/10.1016/j.tcb.2016.05.002.

21. Harkema L, Youssef SA, de Bruin A. Pathology of mouse models of accelerated aging. Vet Pathol. 2016;53(2):36689. https://doi.org/10.1177/0300985815625169.

22. Kalueff AV, Minasyan A, Keisala T, Shah ZH, Tuohimaa P. Hair barbering in mice: implications for neurobehavioural research. Behav Process. 2006;71:8-15. https://doi. org/10.1016/j.beproc.2005.09.004.

23. Kennedy BK, Berger SL, Brunet A, Campisi J, Cuervo AM, Epel ES, et al. Geroscience: linking aging to chronic disease. Cell. 2014;159:709-13. https://doi.org/10.1016/j. cell.2014.10.039.

24. Khan AU, Mei YH, Wilson T. A proposed function for spermine and spermidine: protection of replicating DNA against damage by singlet oxygen. Proc Natl Acad Sci. 1992;89:11426-7. https://doi.org/10.1073 /pnas.89.23.11426.

25. Kim K, Choe HK. Role of hypothalamus in aging and its underlying cellular mechanisms. Mech Ageing Dev. 2019;177:74-9. https://doi.org/10.1016/j.mad.2018.04.008.

26. Lagishetty CV, Naik SR. Polyamines: potential antiinflammatory agents and their possible mechanism of action. Indian J Pharm. 2008;40:121-5. https://doi. org/10.4103/0253-7613.42305.

27. Lee $\mathrm{C}$, Longo V. Dietary restriction with and without caloric restriction for healthy aging. F1000Research. 2016;5. https://doi.org/10.12688/f1000research.7136.1.

28. Leiter EH, Premdas F, Harrison DE, Lipson LG. Aging and glucose homeostasis in $\mathrm{C} 57 \mathrm{BL} / 6 \mathrm{~J}$ male mice. FASEB J. 1988;2:2807-11. https://doi.org/10.1096 /fasebj.2.12.3044905.

29. Liberale L, Montecucco F, Tardif J-C, Libby P, Camici GG. Inflamm-ageing: the role of inflammation in age-dependent cardiovascular disease. Eur Heart J. 2020;41:2974-82. https://doi.org/10.1093/eurheartj/ehz961.

30. Longo VD, Mattson MP. Fasting: molecular mechanisms and clinical applications. Cell Metab. 2014;19:181-92. https://doi.org/10.1016/j.cmet.2013.12.008.

31. López-Otín C, Blasco MA, Partridge L, Serrano M, Kroemer G. The hallmarks of aging. Cell. 2013;153:1194 217. https://doi.org/10.1016/j.cell.2013.05.039.

32. Madeo F, Carmona-Gutierrez D, Hofer SJ, Kroemer G. Caloric restriction mimetics against age-associated disease: targets, mechanisms, and therapeutic potential. Cell Metab. 2019;29:592-610. https://doi.org/10.1016/j. cmet.2019.01.018.

33. Madeo F, Eisenberg T, Büttner S, Ruckenstuhl C, Kroemer G. Spermidine: a novel autophagy inducer and longevity elixir. Autophagy. 2010;6:160-2. https://doi.org/10.4161 /auto.6.1.10600.

34. Madeo F, Eisenberg T, Pietrocola F, Kroemer G. Spermidine in health and disease. Science. 2018;359:eaan2788. https://doi.org/10.1126/science.aan2788. 
35. Madeo F, Pietrocola F, Eisenberg T, Kroemer G. Caloric restriction mimetics: towards a molecular definition. Nat Rev Drug Discov. 2014;13:727-40. https://doi.org/10.1038 /nrd4391.

36. Maglione M, Kochlamazashvili G, Eisenberg T, Rácz B, Michael E, Toppe D, et al. Spermidine protects from agerelated synaptic alterations at hippocampal mossy fiber-CA3 synapses. Sci Rep. 2019;9:19616. https://doi.org/10.1038 /s41598-019-56133-3.

37. Miller-Fleming L, Olin-Sandoval V, Campbell K, Ralser M. Remaining mysteries of molecular biology: the role of polyamines in the cell. J Mol Biol. 2015;427:3389-406. https://doi.org/10.1016/j.jmb.2015.06.020.

38. Mirrione MM, Schiffer WK, Fowler JS, Alexoff DL, Dewey SL, Tsirka SE. A novel approach for imaging brainbehaviour relationships in mice reveals unexpected metabolic patterns during seizures in the absence of tissue plasminogen activator. NeuroImage. 2007;38:34-42. https://doi. org/10.1016/j.neuroimage.2007.06.032.

39. Mohr U, Dungworth DL, Capen CC. Pathobiology of the aging mouse. 1st ed, vol. 1. Washington, DC: Intl Life Sciences Inst. 1996. https://www.si.edu/object/siris sil 444836 .

40. Morselli E, Mariño G, Bennetzen MV, Eisenberg T, Megalou E, Schroeder S, et al. Spermidine and resveratrol induce autophagy by distinct pathways converging on the acetylproteome. J Cell Biol. 2011;192:615-29. https://doi. org/10.1083/jcb.201008167.

41. Muñoz-Lorente MA, Cano-Martin AC, Blasco MA. Mice with hyper-long telomeres show less metabolic aging and longer lifespans. Nat Commun. 2019;10:4723. https://doi. org/10.1038/s41467-019-12664-x.

42. Parodi C, Hardman JA, Allavena G, Marotta R, Catelani T, Bertolini M, et al. Autophagy is essential for maintaining the growth of a human (mini-)organ: evidence from scalp hair follicle organ culture. PLoS Biol. 2018;16:e2002864. https://doi.org/10.1371/journal.pbio.2002864.

43. Pettan-Brewer C, Treuting PM. Practical pathology of aging mice. Pathobiol Aging Age Relat Dis. 2011;1. https://doi. org/10.3402/pba.v1i0.7202.

44. Pietrocola F, Lachkar S, Enot DP, Niso-Santano M, BravoSan Pedro JM, Sica V, et al. Spermidine induces autophagy by inhibiting the acetyltransferase EP300. Cell Death Differ. 2015;22:509-16. https://doi.org/10.1038/cdd.2014.215.

45. Pietrocola F, Pol J, Vacchelli E, Rao S, Enot DP, Baracco $\mathrm{EE}$, et al. Caloric restriction mimetics enhance anticancer immunosurveillance. Cancer Cell. 2016;30:147-60. https://doi.org/10.1016/j.ccell.2016.05.016.

46. Puleston DJ, Buck MD, Klein Geltink RI, Kyle RL, Caputa G, O'Sullivan D, et al. Polyamines and eIF5A hypusination modulate mitochondrial respiration and macrophage activation. Cell Metab. 2019;30:352-363.e8. https://doi. org/10.1016/j.cmet.2019.05.003.

47. Ramot Y, Tiede S, Bíró T, Abu Bakar MH, Sugawara K, Philpott MP, et al. Spermidine promotes human hair growth and is a novel modulator of human epithelial stem cell functions. PLoS One. 2011;6:e22564. https://doi. org/10.1371/journal.pone.0022564.

48. Rider JE, Hacker A, Mackintosh CA, Pegg AE, Woster PM, Casero RA. Spermine and spermidine mediate protection against oxidative damage caused by hydrogen peroxide.
Amino Acids. 2007;33:231-40. https://doi.org/10.1007 /s00726-007-0513-4.

49. Rinaldi F, Marzani B, Pinto D, Ramot Y. A spermidinebased nutritional supplement prolongs the anagen phase of hair follicles in humans: a randomized, placebo-controlled, double-blind study. Dermatol Pract Concept. 2017;7:17-21. https://doi.org/10.5826/dpc.0704a05.

50. Romano AD, Serviddio G, de Matthaeis A, Bellanti F, Vendemiale G. Oxidative stress and aging. J Nephrol. 2010;23(Suppl 15):S29-36.

51. Sakamoto A, Terui Y, Yoshida T, Yamamoto T, Suzuki H, Yamamoto K, et al. Three members of polyamine modulon under oxidative stress conditions: two transcription factors (SoxR and EmrR) and a glutathione synthetic enzyme (GshA). PLoS One. 2015;10:e0124883. https://doi. org/10.1371/journal.pone.0124883.

52. Sarna JR, Dyck RH, Whishaw IQ. The Dalila effect: C57BL6 mice barber whiskers by plucking. Behav Brain Res. 2000;108:39-45. https://doi.org/10.1016/S0166-4328 (99)00137-0.

53. Schwarz C, Stekovic S, Wirth M, Benson G, Royer P, Sigrist SJ, et al. Safety and tolerability of spermidine supplementation in mice and older adults with subjective cognitive decline. Aging. 2018;10:19-33. https://doi.org/10.18632 /aging. 101354.

54. Strait JB, Lakatta EG. Aging-associated cardiovascular changes and their relationship to heart failure. Heart Fail Clin. 2012;8:143-64. https://doi.org/10.1016/j. hfc.2011.08.011.

55. Sun H, Xiang J, Liu Y, Li L, Li Q, Xu G, et al. A stabilizing and denaturing dual-effect for natural polyamines interacting with G-quadruplexes depending on concentration. Biochimie. 2011;93:1351-6. https://doi.org/10.1016/j. biochi.2011.06.007.

56. Tain LS, Jain C, Nespital T, Froehlich J, Hinze Y, Grönke S, et al. Longevity in response to lowered insulin signaling requires glycine $\mathrm{N}$-methyltransferase-dependent spermidine production. Aging Cell. 2020;19:e13043. https://doi. org/10.1111/acel.13043.

57. Takkinen JS, López-Picón FR, Al Majidi R, Eskola O, Krzyczmonik A, Keller T, et al. Brain energy metabolism and neuroinflammation in ageing APP/PS1-21 mice using longitudinal ${ }^{18}$ F-FDG and ${ }^{18}$ F-DPA-714 PET imaging. J Cereb Blood Flow Metab. 2017;37:2870-82. https://doi. org/10.1177/0271678X16677990.

58. Terai M, Izumiyama-Shimomura N, Aida J, Ishikawa N, Sawabe M, Arai T, et al. Association of telomere shortening in myocardium with heart weight gain and cause of death. Sci Rep. 2013;3:2401. https://doi.org/10.1038/srep02401.

59. Thorn SL, deKemp RA, Dumouchel T, Klein R, Renaud JM, Wells RG, et al. Repeatable noninvasive measurement of mouse myocardial glucose uptake with 18F-FDG: evaluation of tracer kinetics in a type 1 diabetes model. J Nucl Med. 2013;54:1637-44. https://doi.org/10.2967 /jnumed.112.110114.

60. Vary JC. Selected disorders of skin appendages-acne, alopecia, hyperhidrosis. Med Clin North Am. 2015;99:1195211. https://doi.org/10.1016/j.mcna.2015.07.003.

61. Vera E, Bernardes de Jesus B, Foronda M, Flores JM, Blasco MA. The rate of increase of short telomeres predicts 
longevity in mammals. Cell Rep. 2012;2:732-7. https://doi. org/10.1016/j.celrep.2012.08.023.

62. Vera E, Bernardes de Jesus B, Foronda M, Flores JM, Blasco MA. Telomerase reverse transcriptase synergizes with calorie restriction to increase health span and extend mouse longevity. PLoS One. 2013;8:e53760. https://doi. org/10.1371/journal.pone.0053760.

63. von Zglinicki T. Oxidative stress shortens telomeres. Trends Biochem Sci. 2002;27:339-44. https://doi.org/10.1016 /s0968-0004(02)02110-2.

64. Wang J, Li S, Wang J, Wu F, Chen Y, Zhang H, et al. Spermidine alleviates cardiac aging by improving mitochondrial biogenesis and function. Aging. 2020;12:650-71. https://doi.org/10.18632/aging.102647.

65. Ward JM, Anver MR, Haines DC, Benveniste RE. Chronic active hepatitis in mice caused by Helicobacter hepaticus. Am J Pathol. 1994;145:959-68.

66. World Health Organization (2018) Global Health Estimates 2016: Disease burden by Cause, Age, Sex, by Country and by Region, 2000-2016. Geneva. In: WHO. http://www.who. int/healthinfo/global_burden_disease/estimates/en/. Accessed 7 Apr 2020.

67. Xu Z, Duc KD, Holcman D, Teixeira MT. The length of the shortest telomere as the major determinant of the onset of replicative senescence. Genetics. 2013;194:847-57. https://doi.org/10.1534/genetics.113.152322.

68. Yabuki A, Yamato O, Suzuki S. Age-dependent changes in the kidney morphology of female DBA/2 mice. Exp Anim. 2009;58:53-6. https://doi.org/10.1538/expanim.58.53.

69. Zhang H, Alsaleh G, Feltham J, Sun Y, Napolitano G, Riffelmacher $\mathrm{T}$, et al. Polyamines control eIF5A Hypusination, TFEB translation, and autophagy to reverse B cell senescence. Mol Cell. 2019;76:110-125.e9. https://doi.org/10.1016/j.molcel.2019.08.005.

Publisher's note Springer Nature remains neutral with regard to jurisdictional claims in published maps and institutional affiliations. 